\title{
SEE THE UNSEEN WITH UBM: UNILATERAL MULTIPLE IRIDO-CILIARY CYSTS - A RARE CASE REPORT
}

Kaushal Kumar ${ }^{1}$, Shivakumar M², Naren Shetty³, Vishma Prabhu ${ }^{4}$

\section{HOW TO CITE THIS ARTICLE:}

Kaushal Kumar, Shivakumar M, Naren Shetty, Vishma Prabhu. "See the unseen with UBM: unilateral multiple irido-ciliary cysts - a rare case report". Journal of Evolution of Medical and Dental Sciences 2013; Vol. 2, Issue 40, October 07; Page: 7743-7746.

INTRODUCTION: Irido- ciliary cysts are uncommon occurrence in the human eye. It is broadly classified as primary cyst and secondary cysts. ${ }^{1}$ Usuallyasymptomatic. Commonly goes undiagnosed on a busy OPD day or is accidently found on dilatation of the pupil. This case report stresses the importance of dilating every OPD patient and assessing of both anterior and posterior segments and doing UBM for patients with shallow anterior/ variable anterior chamber depth.

CASE REPORT: A 52yr old female patient on a routine microscopic examination in Rajarajeshwari Medical College and Hospital Department of Ophthalmology was found to have bilateral cortical cataract with nuclear sclerosis grade 2 . On gonioscopy the anterior chamber angle from 3 '0 clock to 8'0 clock was obscured rest of the angle was wide open. The rest of the anterior chamber was normal. On gonioscopy the left eye's anterior chamber angle from 3'0 clock to 8'0 clock was obscured, rest of the angle was wide open. Intra ocular pressure was normal.

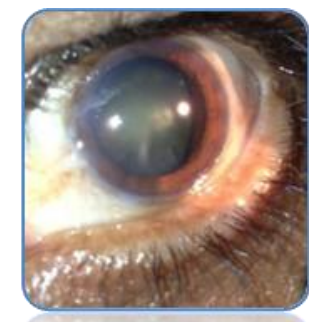

Fig. 1

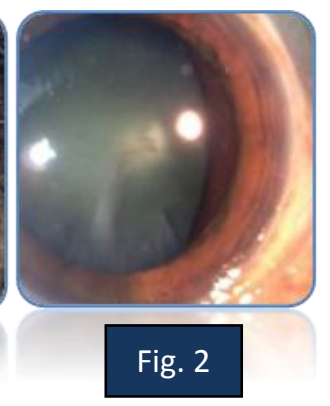

On dilation the left eye had a smooth brown pigmented crescentic single lesion posterior to the iris extending for 3'0 clock to 6'0 clock (fig $1 \& 2$ ). It was a translucent mass. Posterior segment of both eyes were normal. We suspected it to be a pigmented epithelial iris cyst, a ciliary body cyst or both. She had no history of use of drugs/ trauma/surgery.

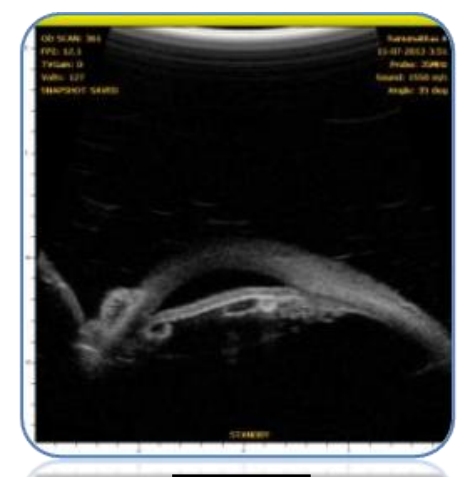

Fig. 3

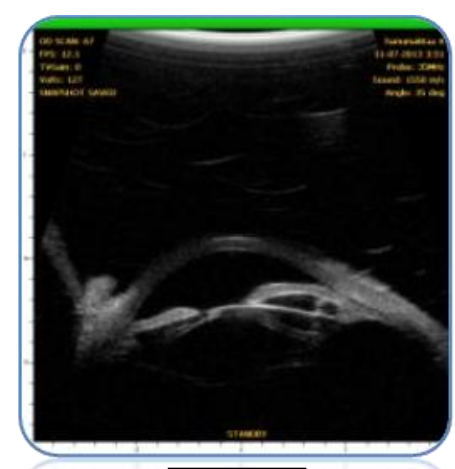

Fig. 4

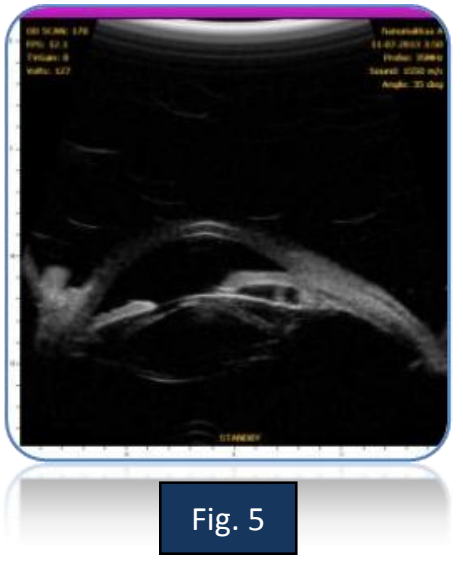

Journal of Evolution of Medical and Dental Sciences/ Volume 2/ Issue 40/ October 07, 2013

Page 7743 
On ultrasound biomicroscopy (UBM) we found multiple echo-free cysts present posterior to the iris, involving the iris and ciliary body extending from 3'0 clock to 8'0 clock with localized angle closure in area of the presence of the cysts (Figure3, 4 \& 5). So we diagnosed it to be as left eye multiple irido-ciliary cyst occluding the anterior chamber angle from 3' 0 clock to 8' 0 clock position. The patient was put under observation and asked to follow-up every 6 months.

DISCUSSION: Iris cyst can be primary or secondary. Shields proposed a classification system based on site /origin and an underlying cause. ${ }^{1}$

\section{A) Primary cysts}

A. Cysts of the pigment epithelium

1. Central (Pupillary margin)

2. Midzonal

3. Peripheral (irido- ciliary)

4. Dislodged

a. Anterior chamber

b. Vitreous chamber

B. Cysts of iris stroma

1. Congenital

2. Acquired

\section{B) Secondary cysts}
A. Epithelial
1. Epithelial downgrowth cysts
a. Postsurgical
b. Post Traumatic
2. Pearl Cysts
3. Drug induced cysts
B. Parasitic

Primary cysts: It is a epithelial lined space which involves a portion of the iris and doesn't have recognizable etiology. Primary cyst can arise from iris pigmented epithelium / iris stroma. ${ }^{1}$

The primary epithelial cysts are unilateral or bilateral, solitary or multiple globular structures which may be brown or transparent depending whether they arise in the iris epithelium or irido-ciliary epithelium respectively. The cysts may be located in the papillary border, mid zone or iris root. Occasionally they get dislodged and float freely in the anterior chamber. The vast majority are asymptomatic and innocuous. Rarely large cysts may obstruct vision and require treatment with argon laser photocoagulation. ${ }^{2}$

The primary stromal cysts present in the first years of life. ${ }^{3,4}$ There appears to be no sex predilection. 3,4,5 They are solitary, unilateral, have a smooth translucent anterior wall and contain fluid. The cysts may be dormant for many years or suddenly enlarge and cause secondary glaucoma, corneal decompensation and show a fluid-debris level reminiscent of a pseudo-hypopyon. A number of associated findings have been found with primary iris stromal cysts, including corneal edema, ${ }^{3,6}$ subluxation of the lens, ${ }^{7}$ iritis, ${ }^{6}$ intraocular pressure elevation, ${ }^{6}$ "mucogenic" glaucoma, ${ }^{8}$ 


\section{CASE REPORT}

cataract, ${ }^{6}$ band keratopathy, ${ }^{6}$ corneal touch, ${ }^{9}$ and hyphema. ${ }^{3}$ Although spontaneous regression can occur, most require treatment by needle aspiration or excision. Injection of ethanol into the cyst for one minute may avoid the need for excision of a recalcitrant cyst. ${ }^{2}$

Secondary cysts: It is caused by epithelial downgrowth following trauma /surgery/drugs, eg. Pilocarpine, echothiophate, etc. These cysts are usually benign and often do not cause any problem. However sometimes they enlarge and produce secondary glaucoma, visual impairment by blocking the visual axis or dislodge into anterior chamber or vitreous cavity. Treatment includes observation, surgical removal, and laser ablation. ${ }^{1}$

Pearl cysts are small, white, solid lesions with opaque walls located in the stroma and are not connected to the wound.

Prolonged use of long-acting miotics may be associated with usually bilateral, small, multiple cysts located along the papillary border. Their development can be prevented by the use of topical phenylephrine $2.5 \%$.

Parasitic cysts are very rare. ${ }^{2}$

CONCLUSION: Irido-ciliary cysts are rare in a human eye. Here is a 52 year old female who came for a general eye examination with a fairly normal anterior segment pre dilatation, was found to have a single epithelial pigmented iris/ irido-ciliary cysts post dilation and on UBM there were multiple irido-ciliary cysts. So every patient who comes to our OPD after assessment of anterior chamber must be fully dilated and once again the anterior segment and posterior segment has to be examined in detail. But sometimes even after complete dilatation iris / ciliary body cyst might get missed. UBM plays a very vital role in the anterior segment assessment. So it would be better to do a UBM scan in all cases of shallow anterior chamber or if there is any occlusion of the angle.

\section{REFERENCE:}

1. Shields JA. Primary cysts of the iris. Trans Am Ophthalmol Soc 1981; 79:771.

2. Jack J Kanski Clinical Ophthalmology sixth edition pg 523-524.

3. T. Harisson Butler A case of cyst of the iris Trans Ophthalmol Soc UK, 41 (1921), pp. 452455.

4. B.A. Klien, G.S. Tanner Congenital epithelial cyst of the iris stroma Am J Ophthalmol, 55 (1963), pp. 291-295.

5. G. Naumann, W.R. Green Spontaneous non pigmented iris cysts Arch Ophthalmol, 78 (1967), pp. 496-500.

6. R.D. Grutzmacher, T.D. Lindquist, M.E. Chittum et al. Congenital iris cysts Br J Ophthalmol, 71 (1987), pp. 227-234.

7. J. Mullaney, C. Fitzpatrick Idiopathic cyst of the iris stroma. Am J Ophthalmol, 76 (1973), pp. 64-68.

8. W.E. Layden, Torczynski E, Font RL. Mucogenic glaucoma and goblet cell cyst of the anterior chamber Arch Ophthalmol, 96 (1978), pp. 2259-2263.

9. G.O.H. Naumann, V. Rummelt Congenital non pigmented epithelial iris cyst removed by block-excision Graefes Arch Clin Exp Ophthalmol, 228 (1990), pp. 392-397. 


\section{AUTHORS:}

1. Kaushal Kumar

2. Shivakumar M.

3. Naren Shetty

4. Vishma Prabhu

\section{PARTICULARS OF CONTRIBUTORS:}

1. Professor, Department of Ophthalmology, Rajarajeshwari Medical College and Hospital.

2. Professor, Department of Ophthalmology, Rajarajeshwari Medical College and Hospital.

3. Post Graduate, Department of Ophthalmology, Rajarajeshwari Medical College and Hospital.

4. Post Graduate, Department of Ophthalmology, Rajarajeshwari Medical College and Hospital.

\section{NAME ADDRESS EMAIL ID OF THE CORRESPONDING AUTHOR:}

Dr. Kaushal Kumar,

Rajarajeshwari Medical College and Hospital, Kambipura, Kengeri Hobli,

Mysore Road, Bangalore - 72 .

Email -drkk61@gmail.com

Date of Submission: 25/09/2013.

Date of Peer Review: 26/09/2013.

Date of Acceptance: 29/09/2013.

Date of Publishing: 04/10/2013 